\title{
A selected annotated bibliography of the resources on the perceptions and attitudes in relation to people who stutter: covering the period from 1990 to the present day
}

By

Kyu Won Hwang

Submitted to the School of Information Management, Victoria University of Wellington in partial fulfilment of the requirements for the degree of Master of Library and Information Studies 


\section{Ackmowledgement}

There are two important people who I would like to extend my sincerest gratitude to: my project supervisor Alan Smith and Lynley Stone. Without their help, support, guidance and patience, this bibliography would never have been able to come to being. I thank Bruce and Nina Whitfield for their continued encouragement and many phone calls. I am also grateful to the McGuire Programme and its brave people. This journey has been of my own journey.

I would like to dedicate this small work to those who do not give upon their battles against one of the most baffling communication disorders of all time, stuttering.

\section{Let's keep moving forward.}




\section{Disclaimer}

The purpose of this bibliography is for educational and informational purposes only in regard to the subject matter covered and should not be regarded or interpreted in any other way. If medical or other expert assistance is required, the reader is strongly recommended to seek out the services of a competent professional advice. The author shall have neither liability nor responsibility to any person or entity with respect to any loss or damage caused, or alleged to be caused, directly or indirectly by the information provided in this research. By proceeding to the contents page, you indicate that you have accepted these terms and conditions. 


\section{Contents}

Page

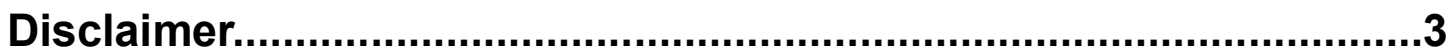

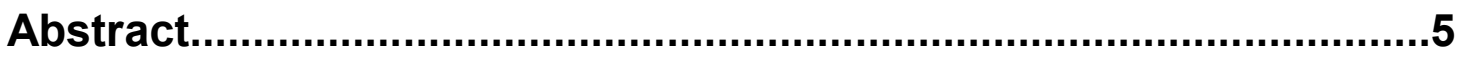

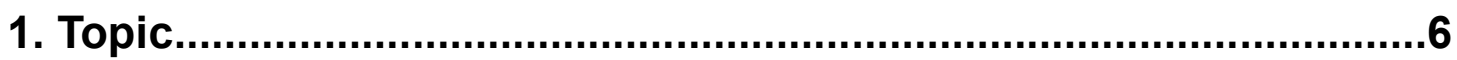

2. Problem Statement ......................................................................6

3. Theme of Bibliography and Its Justification...................................

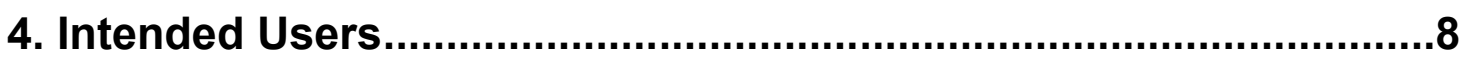

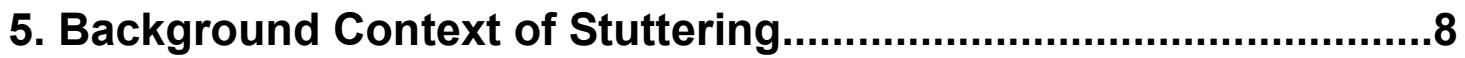

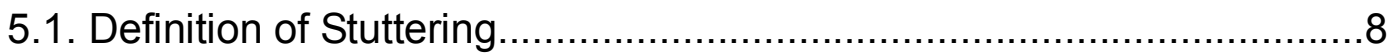

5.2. Onset, Prevalence and Incidence of Stuttering ..................................10

5.3. Features of Stuttering Behaviour.....................................................11

5.4. Feelings and Attitudes of People who stutter...................................12

6. Scope and Delimitations................................................................13

7. Format and Arrangement of Entries..............................................14

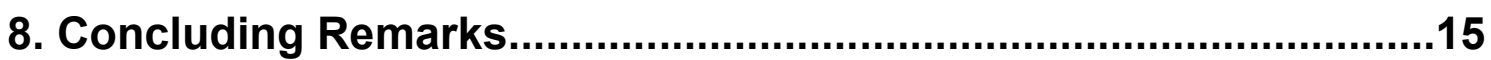

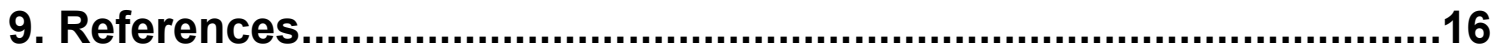

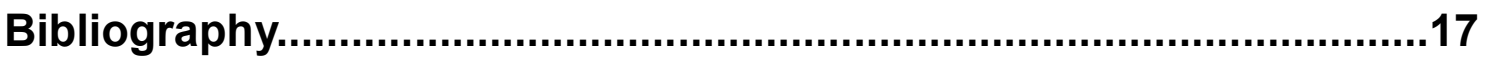

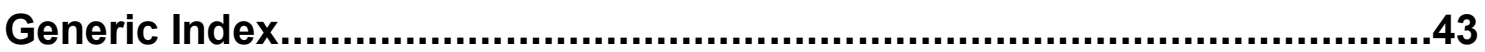




\begin{abstract}
Stuttering, or fluency disorder, is one of the most baffling and debilitating communication disorders of all time. Research has shown that people with stuttering suffer from a range of negative emotions and that strong negative stereotypes of stutterers exist in society. Some of the most important factors in stuttering treatment have been known to be the perceptions and attitudes toward and of stutterers. To assist practitioners and researchers in the related field, a selective annotated bibliography has been complied on the basis of the two key concepts of perception and attitude and their relationships with stuttering. Access points are offered via generic index at the end.
\end{abstract}




\section{Topic}

The topic for this project is a selected annotated bibliography of the resources on the perceptions and attitudes in relation to people who stutter: covering the period from 1990 to the present day at the time of writing (June 2009).

\section{Problem Statement}

Stuttering can be a very appropriate topic for a bibliography because it exists in all parts of the world irrespective of race, culture, language, age or sex, etcetera.

Any research on stuttering would be relevant not only to New Zealand but also to the rest of the world, as stuttering occurs in every country with a prevalence rate of $1 \%$ of the total population. For instance, according to that rate, there are nearly 30,000 people who stutter in New Zealand alone. The Republic of Korea (South Korea) has about 480,000; there are more than 3 million in the USA. For these reasons, one would not be able to argue in full confidence that a bibliography of stuttering would be irrelevant to the context of New Zealand, as it is very much an international phenomenon.

To the author's best knowledge, there exists a great gap of knowledge in literature on and about the subject of stuttering. Based on the search on the union catalogue of WorldCat, there appears to be only 13 items of bibliographical research on stuttering. The latest one was published back in the 1970s, and there has been no major work found since then. What's more, no reliable bibliographies were found on the Te Puna National Bibliographic Database of New Zealand. In addition, the searches across some major scientific databases (Scopus, PsychInfo \& MedLine) yielded extremely poor search results (e.g. only 2-3 items) in terms of stuttering during a period from year 2000 and the present day, not only in New Zealand but also in the international research context. Consequently, there appears to be a great gap of knowledge in stuttering literature, which presents a great need for compiling a bibliography. Nonetheless, the field of stuttering itself can be very broad as any subject of investigation. For example, in the 
stuttering literature alone, there are a range of areas such as etiology, symptomatology, and psychology of stutterers, treatment, intervention, prevention, and so forth. Hence it is appropriately necessary to narrow down to a specific subject area, which is discussed in more details next.

N.B. Throughout this report, the two terms of stutterer and person who stutters [PWS] will be used interchangeably when the person with stuttering disorder is referred to. The term PWS started to be used since the early 1990s in the notion that stuttering is something the person does, not the single characteristic that defines the sufferer (Starkweather \& Givens-Ackerman, 1997).

\section{Theme of the Bibliography and Its Justification}

The main theme of this bibliography is centred on two keywords; 'perception' and 'attitude'. As is discussed later, in general a large number of people who stutter suffer from the self-hate, guilt, embarrassment and all sorts of negative emotions because of their own perceptions about themselves and the perceptions that other people give upon them tend to be negative.

One of the most important factors to help stutterers with their recovery is their attitude towards their problems caused by the presence of stuttering (speech, emotional, social problems or whatever kind). Perception provides a base for what sort of emotions stutterers feel. Attitude defines stutterers' ways of dealing with the perceptions of themselves and of others. In addition, most of conventional stuttering therapies in the past that were offered by speech pathologists really did not address well enough the twin issues of the perceptions and attitudes towards people who stutter. However, it may be added that these issues are being given more recognition in stuttering treatment these days. 


\section{Intended Users}

The primary target audience of this bibliography are speech therapists and researchers in the related field of stuttering research. The bibliography deals with academic resources with some degrees of technicality. Hence, it is expected to be able to benefit professional people involved in speech therapy as part or all of their work. However, this bibliography was written having laypeople in mind because some laypersons who stutter themselves might also find this helpful for their own interest. They are the secondary audience that this bibliography is directed at.

\section{Background Context on Stuttering}

\subsection{Definition of Stuttering}

Van Riper and Erickson (1996) define stuttering — also referred to as fluency disorderas follows; "Stuttering occurs when the forward flow of speech is interrupted abnormally by repetitions or prolongations of a sound, syllable, or articulatory posture, or by avoidance and struggle behaviours..." (p. 254). As clear-cut as that definition on stuttering may sound, stuttering can be defined in simple and clear terms when it is viewed from the viewpoint of speech-language pathology. However, when stuttering is considered from the viewpoint of its impact on people's lives, any single definition cannot precisely describe all the emotional and physical baggage that comes with it.

Starkweather and Givens-Ackerman (1997) emphasized that stuttering is a devastating communication disorder which affects approximately $1 \%$ of the population at any given time. It occurs regardless of time, culture, or race. The oldest record of stuttering in history appeared in the ancient Egyptian recordings some 4,500 years ago. Unlike most language disorders, stuttering may have complete dominance over a person's life. It controls the person's sense of identity by making speaking, which is such an easy task for almost everyone, an agonizingly painful experience. Since spoken language is one very essential part of human existence, stutterers are very likely to constantly experience 
frustration, shame, humiliation, anger, and resentment, and develop a sense of inadequacy and even guilt (Starkweather \& Given-Ackerman, 1997). In this sense, stuttering can be viewed as a kind of disability that inflicts pain on people's lives.

Stuttering is quite remarkable in terms of its variability (Kehoe, 1999; Van Riper \& Erickson, 1996). Stuttering differs from most disorders in the sense that it is not always obvious in terms of its manifestations. Stutterers-or people who stutter-appear perfectly normal until they open their mouth and start to struggle to utter strings of words. Besides, the startling fact about stuttering is that stutterers do not always stutter. This feature of stuttering is what makes it so unique as well as frustrating. Deaf people do not have sudden bursts of good hearing. Paraplegics cannot sometimes rise out of their wheelchair and walk. But stutterers can produce perfectly fluent sentences at times. They can often speak fluently when they are alone, reading in chorus, singing a song, by changing their manner of speaking, thinking differently, or even seeing their speech therapist walk into the room. However, this kind of temporary fluency does not give stutterers much confidence in their speech (Jezer, 1997). It tends to make the next bout of dysfluency more difficult for stutterers to accept, and they will try harder not to let stuttering happen again. Quite often their hardest attempt not to stutter ends in failure. This only tends to reinforce a sense of uncertainty and insecurity among stutterers themselves.

Another intriguing feature of stuttering is that stutterers usually have poor awareness of their own stuttering (Kehoe, 1999; Starkweather \& Given-Ackerman, 1997). In the midst of a speech block, they may feel mentally 'blank'. Some researchers have found that stutterers feel as if they are passing out, yet they know they will stay conscious somehow. They lose awareness of where they are, what they are doing, who they are speaking to, or anything in their immediate environment (Van Riper \& Erickson, 1996). One person who stutters talks about his stuttering moment, "When I stutter, my mind would come to a kind of blank state for a second, a kind of pause. I can't feel anything and can't think" (cited in Kehoe, 1999). After this horrible moment has passed by, many stutterers typically feel ashamed, embarrassed and even guilty. Some researchers suggest that repeated exposure to this kind of negative communication experience could be contributing factors to what makes people who stutter go on to develop a poor attitude 
towards speaking (e.g., Miller \& Watson, 1992). Moreover, stutterers possess a wide range of coping strategies that they have developed to get through their difficult times. These strategies are often referred to as 'tricks'. The most common trick is avoidance (Peters \& Guitar, 1991; Starkweather \& Givens-Ackerman, 1997). This includes avoiding speaking words that the stutterer thinks hard to utter and avoidance of situations in which a great deal of speaking is required.

Finally, there are more boys who stutter than girls. The typical sex ratio is $3: 1$ (Bloodstein, 1993). Girls tend to begin to stutter earlier but are more likely to grow out of it. Boys start stuttering later and are less likely to outgrow it (Kehoe, 1999). The sex ratio also increases with advancement of age. About $80 \%$ of adult stutterers are male (Guitar, 1998; 2006).

\subsection{Onset, Prevalence and Incidence of Stuttering}

Sometimes it is difficult to measure exactly when stuttering starts to occur in children. This is because most information on the onset of stuttering comes from parents' reports, and the parents are often uncertain about the exact time of onset and the particular symptoms that first drew their attention (Peters \& Guitar, 1991). In spite of these uncertainties, there is general consensus among researchers that the typical age for stuttering to begin is between 2 and 5 years of age (Kehoe, 1999).

The term prevalence refers to the numbers of cases of a disease in a population at a given time. The prevalence of stuttering informs us of how many people currently stutter (Peters \& Guitar, 1991). Bloodstein (1987) reviewed 38 studies of stuttering prevalence among school children in the U.S.A., Europe, Africa, Australia, and the West Indies from 1893 to 1981 . From the analysis of the results of these studies, he concluded that the prevalence of stuttering is about $1 \%$ of the whole population. That means approximately $1 \%$ of the school-aged children stutter at any given time. A study by Andrews et al. (1983) also reached the same conclusion. In regard to the prevalence in the adult population, Bloodstein (1987) suggests that the prevalence in adults would be less than 
$1 \%$, as prevalence figures tend to decrease after puberty.

The incidence of stuttering is an index of how many people have experienced an episode of stuttering at some time in their lives (Peters \& Guitar, 1991). The lifetime incidence of stuttering is estimated at about 5\% (Andrews et al., 1983). In other words, $5 \%$ of the population would remember stuttering at some point in childhood. The difference between the incidence rate $(5 \%)$ and the prevalence rate $(1 \%)$ is of particular interest. It indicates that most individuals who stutter at some time in life do recover from stuttering without formal treatment or intervention.

\subsection{Features of Stuttering Behaviours}

People who stutter exhibit a range of behaviours that are unique to fluency disorder(s). Researchers in the stuttering literature have come up with the two terms to describe symptomatic behaviours shown by people who stutter; they are "core behaviours" and “secondary behaviours" (Van Riper, 1982; Guitar, 1998; Guitar, 2006; Kehoe, 1999).

Core behaviours mean the involuntary basic muscle movements of speech articulators (tongue, mouth and lips) that are central to the stuttering disorder. These are repetitions, prolongations and blocks. Repetitions are observed most commonly in children who are starting to speak. These are simple repetitions of a sound, syllable, or single-syllable word. Prolongations refer to speech anomalies where a sound or air flow keeps going while the articulators are not moving at all. And blocks occupy the centre of the core behaviours in which the flow air or voice is completely halted and sometimes the movement of the articulators is stopped as well. Blocks could occur on any level of speech mechanism - respiratory, laryngeal, or articulatory (Guitar, 1998). One thing to note is that people who stutter tend to differ considerably in regard to their individual frequencies of stuttering core behaviours.

There is a set of behaviours also observed in stutterers that often accompanies the core behaviours. They are called secondary behaviours, or colloquially referred to as "tricks", 
which are not directly related to speech production but more like learned reactions to the core behaviours (Guitar, 1998; Kehoe, 1999). These behaviours include (adapted from Kehoe, 1999);

- Physical muscle movements such as eye blinks, head jerks, body spasms, gasping, and/or clenching of teeth or fists.

- Use of "filler" or "starter" sounds and words, such as "um,", "ah,", or "you know,"

- Vocal abnormalities, such as changes in speech rate, speaking in a monotone, adopting an unusual accent, or using odd inflections

- Articulating an unrelated sound, e.g. forming a /t/ sound when trying to say /s/

- Low-frequency tremors in the neck, jaw, and lip muscles

- A set of avoidance behaviours such as not maintaining eye contact during a conversation or choosing to remain silent rather than talking

Many people who stutter perform those behaviours in an attempt to relieve muscle tension in their articulators (avoid the core behaviours). For instance, if one stutterer is in his stuttering block where his vocal cords are completely frozen, he may slap his elbow to escape from the block, which is his 'trick'. The unfortunate thing is the effects of any one trick tend to wear off with the passage of time. After that, the stutterer may resort to another form of trick, and ultimately develops a bag of undesirable habits (Kehoe, 1999).

\subsection{Feelings and Attitudes of People who stutter}

The core and secondary behaviours of stuttering can have significant impacts on the development and shaping of the psyche of people with fluency disorder. Guitar (1998; 2006) explained how the feelings and attitude of persons who stutter may be an ingrained part of their fluency disorder. For example, a child with disposition to stuttering may develop a great difficulty with their speech while learning how to talk. The more they stutter the more frustrated or shameful they can feel, as they become more and more aware that they are unable to say what they want to say as easily as their 
peers do. The difficulty of speaking only aggravates the child's feelings of frustration and embarrassment. Next time they are stuck on a word, they tend to boost their efforts to push it through harder and harder, which only results in more tension in their articulators and hence their stutter getting worse and worse. Then they come to experience more negative feelings towards their speaking, and this turns into some sort of a vicious circle that the stutterer cannot escape from.

By the time stuttering children become an adolescent or even an adult, they are highly likely to have a negative attitude towards their own self (Guitar, 1998). While the children are growing up, they experience more and more stuttering. Therefore, they come to perceive themselves as a person who has a difficulty with speaking. This perception can lead to the development of a negative attitude that affects their whole personality. In addition, that attitude may generate a range of other negative emotions such as guilt, poor self-image, anxiety and depression which are observed in many people who stutter (Silverman, 2004).

What is worthwhile bearing in mind here is that the listeners of people who stutter can play an important role in the formation of negative attitudes of stutterers. Many studies have found that a great many people tend to view stutterers as fearful, introverted, anxious and insecure (Silverman \& Paynter, 1990; Turnbaugh, Guitar \& Hoffman, 1979; Woods \& Williams, 1976). These disapproving stereotypes that the general population hold on stutterers may enhance the stutter's negative attitudes. For this reason, it is critical that addressing the client's negative attitudes and improving them should be one of the major focuses of stuttering treatment (Guitar, 1998; 2006).

\section{Scope \& Delimitations}

This bibliography contains entries for selected journal articles and books composed in the English language. Most of the materials were acquired by the search the core keywords of perception and attitude. These keywords were extracted from analysis of the topic in question, and the number of key words were determined through the same 
process. For instance, through a trial and error process, a core group of keywords, such as 'stuttering', 'perceptions, 'attitude' and 'stereotype, were acquired. In addition, items were searched through a range of the following information sources: (a) academic journals and databases (Journal of Fluency Disorders, ScienceDirect, Scopus, Expanded Academic, ProQuest, etc.), (b) secondary referencing from already acquired items, (c) online catalogues of various university libraries in New Zealand, and (d) the Internet. The selection of materials was performed on the basis of core concept keywords and was expanded from them.

The time limit of the bibliography is set for a period from the year 1990 to the present day (June 2009 at the time of writing). It is duly acknowledged that there are great many studies that are significant for the topic that had been done prior to the set period. The reason for this time limit is to offer a more current picture of relevant pieces of research.

\section{Format and Arrangement of Entries}

The entries of the bibliography followed the American Psychology Association (APA) referencing style for the citation of all the materials quoted here. This is because the majority of all the items are articles from scholarly journals and databases. In addition, the targeted main audience are speech therapists and professional researchers who are already accustomed to this type of citation. Therefore, the APA style is a logical choice for the kind of referencing needed for the bibliography.

The annotation is written in a summary format to provide a brief yet essential gist of a given item. It is composed in the way that they can be informative and evaluative, and give the readers enough information to appraise relevant material. The language used in the annotations is targeted for general audience in order to satisfy the needs of both primary and secondary target audience. The annotation is located below the citation of one entry, with 12-point Times New Roman font used for annotations and 12-point Ariel font for citations. Each entry is distinguished by small visual space between them. 
All the items are sorted out primarily by the names of the author in the alphabetical order. This is because the bibliography deals with one central theme with a defined time period. Any other form of arrangement is considered to be redundant and could potentially be confusing for readers. In the case of the same author, an item of earlier date appears first (in chronologically ascending order). Finally, all the entries were sorted out manually using the Microsoft Word programme.

The index terms have been yielded after all the materials were gathered and analyzed. All the indexing terms were listed and evaluated in terms of whether they could constitute the real parameters (the indexes that add values for searching).

\section{Concluding Remarks}

While gathering items for this research, certain academic journals, especially the Journal of Fluency Disorders, have proved to be a rich source of materials which can be continuously used for future writing. Since stuttering is found in all the cultures and languages through the world, it is predicted that very similar traits will be observed in sources of languages other than English. This bibliography is provided as a selected guide that introduces some of the best material in regard to the covered topic for researchers and practitioners in the field, and the author would welcome any comments or additions to this email address, stutterenglish@hotmail.com. 


\section{References}

Andrews, G., Craig, A., Feyer, A. M., Hoddinott, S., Howei, P., \& Neilson, M. (1983). Stuttering: A review of research findings and theories circa 1982. Journal of Speech and Hearing Disorders, 48, 226-246.

Bloodstein, O. (1987). A handbook on stuttering. Chicago: National Easter Seal Society.

Bloodstein, O. (1993). Stuttering: the search for a cause and cure. Boston: Allyn and Bacon

Guitar, B. (1998). Stuttering: an integrated approach to its nature and treatment (2nd ed.). Baltimore, Md. : Williams \& Wilkins.

Guitar, B. (2006). Stuttering: an integrated approach to its nature and treatment (3rd ed.). Philadelphia: Lippincott Williams \& Wilkins.

Jezer, M. (1997). Stuttering: a life bound up in words. New York: BasicBooks.

Kehoe, T. D. (1999). Stuttering: Science, therapy and practice. Boulder, CO: Casa Futura Technologies

Miller, S. \& Watson, B. C. (1992). The relationship between communication attitude, anxiety, and depression in stutterers and nonstutterers. Journal of Speech and Hearing Researchh, 35, 789-798.

Peters, T. J. \& Guitar, B. (1991). Stuttering: an integrated approach to its nature and treatment. Baltimore: Williams \& Wilkins.

Silverman, F. H. \& Paynter, K. K. (1990). Impact of stuttering on perception of occupational competence. Journal of Fluency Disorders, 15, 87-91.

Silverman, F. H. (1992). Stuttering and other fluency disorders. Englewood Cliffs, NJ: Prentice-Hall.

Silverman, F. H. (2004). Stuttering and other fluency disorders. (3rd ed.). Long Grove, IL.: Waveland Press.

Starkweather, C. W. \& Givens-Ackerman, J. (1997). Stuttering. Austin, Texas: PRO-ED.

Turnbaugh, K. R. \& Guitar, B. E. (1981). Short-term intensive stuttering treatment in a public school setting. Language, Speech and Hearing Services in Schools, 12, 107114.

Van Riper, C. (1982). The nature of stuttering (2nd ed.). Englewood Cliffs, NJ: Prentice-Hall.

Van Riper, C., \& Erickson, R. L. (1996). Speech correction: An introduction to speech pathology and audiology (9th ed.). Boston: Allyn and Bacon.

Woods, C. L. \& Williams, D. E. (1976). Traits attributed to stuttering and normally fluent males. Journal of Speech and Hearing Research, 19, 267-278. 


\section{Bibliography}

1. Al-Khaledi, M., Lincoln, M., McCabe, P., Packman, A. \& Alshatti, T. (2009). The attitudes, knowledge and beliefs of Arab parents in Kuwait about stuttering. Journal of Fluency Disorders, In Press.

This study investigated attitudes, level of knowledge and current beliefs about stuttering in Kuwait. Using an Arabic version of the Public Opinion Survey of Human Attributes Inventory (POSHA-E), which is a universal tool to assess public attitudes towards stuttering, it surveyed 424 parents of 18 governmental schools throughout Kuwait.

It was found that most people in Kuwait are aware of the disorder and have been exposed to the condition, but their level of knowledge about stuttering in general was very low. Given that the profession of speech-language therapy is a relatively new concept in that country, this study shows the importance of the need to educate the general public in Arab countries about stuttering.

2. Anderson, D. (1994). He stammers! That's a pity!: Historical perceptions of stuttering as reflected in the arts. Journal of Fluency Disorders, 19(3), 150.

This article analyses the ways how stuttering has been represented in the arts throughout history, especially the form of opera along with fiction and drama. It presents the summary of how stutterers are described in music as the artists' and society's understanding of stuttering is more developed.

3. Anderson, D. (1997). Changes in attitudes toward cancer, homosexuality, and stuttering 1940-1997. Journal of Fluency Disorders, 22(2), 148.

The author traced the changes in societal and professional perceptions of cancer, homosexuality and stuttering since the 1940s up to 1997. By extracting from various sources such as scholarly publications, popular magazines and newspapers, the article looked at the developments of attitudes as the society has become more tolerant of different conditions. One thing to note is the author's discussion of how changes in attitudes may help the public to be better informed about stuttering.

4. Blood, G. W., Blood, I. M., Tellis, G. \& Gabel, R. (2001). Communication apprehension and self-perceived communication competence in adolescents who stutter. Journal of Fluency Disorders, 26(3), 161-178. 
A group of stuttering adolescents and another group of non-stuttering adolescents were compared to investigate their communication apprehension and self-perceived communication competence. Communication apprehension refers to a person's anxiety or fear to speak to another person.

The two groups were examined on two standardized communication methods, the Personal Report of Communication Apprehension (PRCA-24) and the Selfperceived Communication Competence (SPCC) scales. Analysis of the data revealed that adolescents who stutter exhibited significantly higher levels of communication apprehension and poorer self-perceived communication competence. Especially, they showed high communication apprehension in the two contexts of group discussion and interpersonal conversation. Another important finding was that the more severe their stuttering is, the more likely the adolescents tend to have high communication apprehension and poor self-perception of their communication competence.

5. Blood, G. W., Blood, I. M., Tellis, G. M. \& Gabel, R. M. (2003). A preliminary study of self-esteem, stigma, and disclosure in adolescents who stutter. Journal of Fluency Disorders, 28(2), 143-159.

The main purpose of this study was to see whether stuttering may be a stigmatizing condition in adolescents who stutter. The authors tried to uncover the relationships among social stigma, disclosure technique and self-esteem on the basis of the following assumptions: (1) negative stereotypes towards stutterers exist, (2) social stigma has negative effects, (3) chronic conditions such as stuttering exert negative influences on adolescents, and (4) a possible relationship may exist between stuttering and stigma.

The findings indicated that the majority ( $85 \%$ ) of adolescents who stutter have positive self-esteem, and stuttering is not hugely viewed as a stigmatizing condition by more than the half $(60 \%)$ of the participants. Nevertheless, many reported that they rarely or never openly talked about their stuttering. An interesting result was that younger adolescents (13-15 years) were more likely to perceive stuttering negatively, to consider it to be stigmatizing and to try hid it harder than older ones (16-18 years).

6. Bloodstein, O. (1995). A handbook on stuttering (5th ed.). San Diego, Calif.: Singular Publishing Group.

There are three devoted chapters each of which provides comprehensive information on the makeup of the person who stutters, namely about physical constitution, personality and developmental history. In particular, it contains helpful information 
on the issues of attitude: attitudes of parents of children who stutter, attitudes of stutterers, and attitudes towards stutterers.

7. Collins, C., \& Blood, G. W. (1990) Acknowledgement and severity of stuttering as factors influencing nonstutterers' perceptions of stutterers. Journal of Speech and Hearing Disorders, 55, 75-81.

In the stuttering literature some therapists suggested that people who stutter may be able to elicit more favourable response from their listeners by acknowledging their stutter during the initial encounter. This is referred to as the acknowledgement tactic. The present article examined whether this tactic would be really effective and saw if there were changes in listeners' perceptions of intelligence, personality and appearance of PWS.

Video clips of two mind and two severe male stutterers with presence and absence of acknowledgement of stuttering were shown to 86 female participants. Results indicated that the participants showed clear preference to interacting with stutterers who acknowledged their stuttering. Mild and severe stutterers who acknowledged also were given more positive feedback on intelligence, personality, and appearance. These findings suggest that acknowledgement can have a significant impact on the listeners' perceptions of stutterers, and hence has important implications for stuttering therapies.

8. Craig, A. R. \& Calver, P. (1991). Following up on treated stutterers: Studies of perceptions of fluency and job status. Journal of Speech and Hearing Research, 34, 279-284.

This article examined the perceptions of people who stutter on a fluency shaping technique called Smooth Speech after they received a treatment. The authors carried out four separate studies in order to find out the long-term perceptions of the treated stutterers on their speech.

The first study showed that all the clients were pleased with the results immediately after the treatment, but only the half of them were happy in the long term. The second study revealed that the opportunities for job promotion and upgrade were significantly enhanced for those who maintained good fluency. The third study looked at their employers' perceptions on them where the employers rated them more positively after receiving treatment. The issue of relapse was probed in the last study, which revealed that most of them experienced relapse to some degree. They believed that the reasons were not that they found it uncomfortable to use Smooth Speech but they felt pressured to speak faster in the real world. This study is a good example which shows that examining perceptions of stutterers' own speech after treatment can be a vital research objective. 
9. Craig, A., Tran, Y. \& Craig, M. (2003). Stereotypes towards stuttering for those who have never had direct contact with people who stutter: A randomized and stratified study. Perceptual and motor skills, 97, 235-245.

In order to examine the attitudes of those have had no contact with PWS, 502 people were randomly selected from New South Wales, Australia and interviewed by telephone. Analysis of the data presented a mixed picture of positive and negative responses. The majority of the respondents reported that they considered PWS to be shy, self-conscious, anxious and socially awkward. On the contrary, many said they would not find it uncomfortable to talk to a person who stutters and believed that stutterers had at least average intelligence or higher. Most of them appeared to understand the difficulties of PWS. No significant differences between male and female respondents were found in their attitudes. One noticeable finding was that the vast majority of the respondents had little knowledge about what causes stuttering.

A lot of previous research has demonstrated the existence of widespread negative stereotypes towards people who stutter that is held by the public. Nevertheless, there have not been many studies that used a sample of a population with no previous direct exposure to stutterers. The authors argued that their study was the first of its kind in the sense that it adopted a true randomized and stratified selection of people.

10. Cooper, E. B. \& Cooper, C. S. (1996). Clinician attitudes towards stuttering: Two decades of change. Journal of Fluency Disorders, 21(2), 119-135.

The authors have looked at the changes in the attitudes of 1,198 speech-language pathologists towards stuttering, people who stutter, their parents, therapy, and other issues for the period from 1983 to 1991 following their pilot study (Cooper \& Cooper, 1985). The results of this study were compared with the findings of their first study.

Some notable changes are observed from speech-language pathologists. Modern pathologists seem to move away the traditional view of Johnson's theory which argues that stuttering develops through anxiety caused by negative parental influence, and hence early intervention is not desirable. They are less likely to think stuttering is caused by some psychological problems. The findings also put emphasis for the need of further enhanced education for the related professionals about the correct nature of stuttering.

Note: Cooper, E. B. \& Cooper, C. S. (1985). Clinician attitudes towards stuttering: A decade of change. Journal of Fluency Disorders, 10, 19-33. 
11. Crichton-Smith, I., Wright, J., \& Stackhouse, J. (2003). Attitudes of speech and language therapists towards stammering: 1985 and 2000. International Journal of Language Communication Disorders, 38(3), 213-234.

The findings of previous studies have shown that the attitudes of speech-language therapists (SLT's) toward people who stutter are somewhat negative. But many of them have been centred around therapists in America. The present study had three purposes: (a) to examine more modern attitudes of the therapists in comparison to those studied in 1985, (b) to investigate how training affected therapists' attitudes between generalists and specialists, and (c) to probe the impact of the Lidcombe Programme (LP) on therapists. The LP is an early stuttering intervention programme for children who stutter developed in Australia.

Results showed a considerable shift in therapists' attitudes. Therapists were more likely to accept the idea of early intervention willingly than 15 years ago, and their attitudes toward PWS and parents of PWS have become less negative. The therapists trained under the LP appeared to hold more positive attitudes and beliefs than those who did not.

This article is a valuable source in the sense that it provides information attitudes of the therapists in a country (the UK) other than the USA, and offers good grounds as in why it is necessary ongoing professional education is needed for better care of clients who stutter.

12. Daniels, D. E., Hagstrom, F. \& Gabel, R. M. (2006). A qualitative study of how African American men who stutter attribute meaning to identity and life choices. Journal of Fluency Disorders, 31, 200-215.

This article did a qualitative investigation on how African American men who stutter perceive themselves in terms of communication, identity and life choices. As for the participants in the study, it has been shown that they tend to define their stuttering problems on multi-dimensions, i.e. racial, ethnic and communicative dimensions. The study talks about how their stuttering has constructed their identity and lifestyle in relation to the three dimensions.

This study provides unique insights as it is one of the rare studies to date which have explored the life experience of people who stutter in the minority ethnic group. It lends support to the notion that it is important for speech-language therapists, when they are treating stuttering, to try to learn about the client's personal meaning and experience associated to his or her speech impediment.

13. De Britto Pereira, M. M., Rossi, J. P. \& Borsel, J. V. (2008). Public awareness and knowledge of stuttering in Rio de Janeiro. Journal of Fluency Disorders, 33(1), 24-31. 
This study explored public awareness and knowledge about stuttering of 606 people in Rio de Janeiro, Brazil. The participants were randomly selected on the streets and were asked to respond to the questions on a range of facets of stuttering such as age of onset, incidence, prevalence, gender distribution, cause, treatment, and so forth.

The results indicated that the general public are aware of stuttering disorder as more than half of the respondents said they knew or met a person who stutters. However, their knowledge of stuttering appears to differ according to different aspects. Generally, females tended to have better understanding than males, and younger people were more positive toward treatment options.

This article presents an interesting comparison case to similar studies done in Belgium and China, and can be an important source considering that public awareness of a particular disorder may have an impact on people's attitude towards the person affected.

14. De Nil, L. F., \& Brutten, G. J. (1991). Speech-associated attitudes of stuttering and nonstuttering children. Journal of Speech and Hearing Research, 34(1), 60-66.

This study examined whether children who stutter would hold more negative speech-associated than those who do not. Seventy stuttering children and 271 nonstuttering children in Belgium were tested using a Dutch version of the Communication Attitude Test (CAT). The results showed that stuttering children exhibited poorer attitudes towards their speech and communication than their counterparts. Their attitudes were inclined to become more negative with increase of age.

One of the key findings of this study is that young children who stutter, as young as seven year old, appeared to have considerably negative attitudes towards their speech. This might be an outcome of negative communicative experiences they went through. The findings suggest that it would be necessary to address the negative attitudes in stuttering treatment for young children.

15. Dietrich, S., K. H. Jensen, et al. (2001). Effects of the label "stutterer" on student perceptions. Journal of Fluency Disorders, 26(1), 55-66.

This study had a look into the differences in how ordinary people perceive on the use of different terminologies that refer to people who stutter. Participants responded to two survey forms which included the description of a hypothetical person who stutters. The two forms were different only in terms of the phrases letting the participant know that the person described was a stutterer. The terms used were 
"stutterer", "noun + who stutters" (person who stutters) and "noun + has had a stuttering problem".

The findings revealed after analysis of 544 completed forms found no significant difference among the terms used, unlike some health professionals' argument that the use of person-first terminology would promote the client's well-being.

Research on what effect the label "stutterer" has on the perceptions of people on people who stutter has been scarce. This study shed some light on this topic.

16. Doody, I., Kalinowski, J., Armsn, J. \& Stuart, A. (1993). Stereotypes of stutterers and nonstutterers in three rural communities in Newfoundland. Journal of Fluency Disorders, 18(4), 363-373.

This study looked into whether a negative stereotype on people who stutter exists among residents of 3 rural communities in Newfoundland, Canada. A questionnaire survey that portrayed a hypothetical male adult stutterer was conducted. Participants were instructed to make comparisons between a stutterer and a non-stutterer.

The results were quite surprising, according to the authors, as a strong negative stereotype on stutterers was found despite the fact that a high number of the participants knew people who stutter personally or related to them. The authors speculated that this negative attitude may be originated through the inference on which non-stutterers make based on their feelings they experience during moments of stutter-like speech.

17. Dorsey, M. \& Guenther, R. K. (2000). Attitudes of professors and students toward college students who stutter. Journal of Fluency Disorders, 25, 77-83.

This article looked into the stereotypes that professors and students at American universities held about students who stutter. A survey was conducted using a questionnaire which asked the respondents to make judgements, on a scale from 1 to 7 , on 20 personality items about a hypothetical stuttering student in comparison to a hypothetical average student.

The general findings of the study indicate that the stuttering student was viewed more negatively in his personality traits than the counter-part average student. Both professors and students appeared to hold more negative views on stutterers than on non-stutterers. The rather disturbing result was that the participating professors seemed to have more negative attitudes toward stuttering students than did other students.

This article is particularly useful because the authors raise concerns for the possible consequences of the negative stereotypes about people who stutter that ordinary fluent speakers have. For example, professors and students could avoid interactions 
with stuttering students on the basis of the widespread negative stereotypes on people who stutter. It addresses the importance of the need of educating professors and general students.

18. Evans, D., Healey, E. C., Kawai, N. \& Rowland, S. (2008). Middle school students' perceptions of a peer who stutters. Journal of Fluency Disorders, 33(3): 203-219.

This study investigated middle school students' perceptions towards a similar-aged stuttering student. It looked at the impact of stuttering frequency, Likert statement type (affective, behavioural, cognitive), and the sex of the listener. Sixty-four middle school students aged between 10 and 14 years were shown a video recording in which a male 16 year-old told a joke at 4 different stuttering frequencies, and they rated him on the 11 Likert scale.

It was found that the participants' perceptions on a peer who stutters were affected by the severity of stuttering. The less stuttering frequency was, the more positive ratings were recorded on behavioural statements (speech characteristics) and cognitive statements (thoughts and beliefs). The interesting find was the little difference in how male and female students perceived a male peer who stutters.

Little research done about this kind of area, therefore, this study provides invaluable insights. Plus, it discusses the important relationship between the concept of "fit-in" among teenage peer groups and stuttering frequency.

19. Finn, P., Howard, R. \& Kubala, R. (2005). Unassisted recovery from stuttering: self-perceptions of current speech behavior, attitudes, and feelings. Journal of Fluency Disorders, 30(4): 281-305.

This research looked at the nature of self-recovery from stuttering without any formal intervention or speech therapy, using a semi-structured, open interview approach. It is one of the rare studies that attempted to present a systematic report of recovered stutterers, and it also tried to find out if those who said they showed no sign of stuttering had different self-perceptions on their speech behaviour and related feelings and attitudes in comparison to those who said they still stuttered intermittently.

The interesting results are complete recovery appeared to be possible at least among the participants who said that they no longer stuttered. On the other hand, those who said that they stuttered on occasion reported that they needed to stay vigilant to maintain their fluency in difficult situations. 
20. Franck, A. L., Jackson, R. A., Pimentel, J. T. \& Greenwood, G. S. (2003). School-age children's perceptions of a person who stutters. Journal of Fluency Disorders, 28(1), 1-15.

This study investigated how school-aged children perceive people who stutter. The method was to show a video recording with the speaker either stuttering or not stuttering while reading to fourth and fifth grade students.

The results demonstrated a significant difference between the perceptions that school-aged children possess toward people who stutters and those who do not. It was revealed that even children held a more negative perception of stutterers than non-stutterers as most adult populations do. One thing to note is that the children did not rate stutterers differently in personality and intelligence related traits.

These results lend support to the notion that correct education about stuttering in the school environments is required because children as young as fourth or fifth grades already have negative perceptions toward people who stutter.

21. Gabel, R. M. (2006). Effects of stuttering severity and therapy involvement on attitudes towards people who stutter. Journal of Fluency Disorders, 31(3), 216-227.

The aim of this study was to see whether stuttering severity and therapy involvement would have an impact on the attitudes of non-stutterers towards stutterers. Two hundred and sixty university students were interviewed using a 25-item semantic scale.

Results indicate that one's stuttering severity and knowledge that the person is doing a therapy indeed have an effect on listener's attitudes towards people who stutter. Those who stutter severely were perceived more negatively than those who stutter mildly. Those who were involved in therapy were also perceived more positively than those who were not. This has an important implication for stuttering therapy. In other words, the finding suggests that listeners show positive attitudes to stuttering if they know that the stutterer is doing therapy. Therefore, therapists may need to encourage their clients to disclose that they are involved in therapy.

22. Green, T. (1999). The relationship of self-conception to perceived stuttering severity in children and adults who stutter. Journal of Fluency Disorders, 24(4), 281-292. 
A long-held assumption in the field of fluency disorder is that stuttering influences self-conception of people who stutter. The authors attempted to test this assumption to see whether stuttering really plays a role in the formation of stutterers' selfconceptions by examining the meaning of the experience history of children and adults who stutter. For that, this study explored the two variables of the participants' perceived stuttering severity and the degree to which their self-conception might be built on involvement in social contexts.

The authors argued that their study would able to support to further research on the role of self-conception in people who stutter.

23. Guntupalli, V. K., Kalinowski, J., Nanjundeswaran, C., Saltuklaroglu, T. \& Everhart, D.E. (2006). Psychophysiological responses of adults who do not stutter while listening to stuttering. International Journal of Psychophysiology, $62,1-8$.

The purpose of this study was to examine the psychological and physiological reactions of people who do not stutter when they are exposed to stuttered speech. Fifteen adults were shown 6 video samples of stuttered speech and fluent speech. It was found that the participants' exposure to stuttered speech produced higher skin conductance which suggested increased emotional arousal. Besides, a lower heart rate was also observed and the participants reported experiencing a sense of unpleasantness while watching stuttering.

Based on these findings, the authors hypothesized that the abnormal behaviours associated with stuttering activate the neural mechanism which causes physical arousal, and that such arousal may form the basis of negative stereotypical perceptions towards stutterers. This investigation is of significance in the sense that it presents the first empirical data to listeners' responses at a psychophysiological level.

24. Guntupalli, V. K., Everhart, D. E., Kalinowski, J. Nanjundeswaran, C. \& Saltuklaroglu, T. (2007). Emotional and physiological responses of fluent listeners while watching the speech of adults who stutter. International Journal of Communication Disorders, 42(2), 113-129.

A large body of research has indicated that there are widespread negative stereotypes towards people who stutter in society regardless of few differences in personality structure between stutterers and normal speakers. Yet there has been a lack of empirical data on the physiological and emotional grounds of these 
stereotypes. In an attempt to fill this gap of knowledge, this research examined the physiological and subjective behavioural responses of nonstuttering speakers while they were listening to stuttered speech samples.

Results showed that stuttered speech caused some involuntary physiological responses among fluent speakers. While listening to stuttered speech, fluent speakers exhibited increased skin conductance and lower heart rates than moments of listening to fluent speech. In addition, the participants reported a range of negative feelings during moments of stuttering such as feeling aroused, nervous, uncomfortable, annoyed, and so on. These findings of this study provide empirical data that can shed light on the evolution of negative stereotypes towards people who stutter, and may be used as a guide to help therapists to devise coping methods for PWS.

25. Ham, R. E. (1990). What is stuttering: Variations and stereotypes. Journal of Fluency Disorders, 15(5-6), 259-273.

A random survey of 563 persons living in Tallahassee, Florida, the USA was conducted to find out what kinds of knowledge and opinions the public hold towards stutterers. Results showed that most respondents were unable to provide consistent, accurate definition of stuttering, though they were aware of stuttering and willing to talk about it. Perceptions toward stutterers tended to be stereotypical viewing them as less adequate and poorly adapting.

26. Healey, E. C., Gabel, R. M., Daniels, D. E. \& Kawai, N. (2007). The effects of self-disclosure and non self-disclosure of stuttering on listeners' perceptions of a person who stutters. Journal of Fluency Disorders, 32(1), 51-69.

The study looked into how listener perceptions of a male adult stutterer were influenced with or without disclosure of his stuttering. Ninety non-stutterers participated in the experiment in which they saw one of three types of videotapes that featured a several male who stuttered. The first group of 30 listeners heard the speaker disclose his stuttering at the beginning, and the other 30 participants heard the disclosure at the end. The third group saw a video without disclosure. Then they filled out a set of 6 Likert scale statements and answered open-ended questions.

The authors point out three important findings. Firstly, the stuttering speaker was perceived to be friendlier when he disclosed his stuttering than when he did not. Secondly, self-disclosure appeared to produce more desirable effects when it was used at the beginning of a communication than at the end. Lastly, given the finding 
that $74 \%$ of the listeners reported that the disclosure did not really change their perceptions of the stuttering speaker, it is thought that self-disclosure seems beneficial more for people who stutter than listeners.

27. Hearne, A., Packman, A., Onslow, M. \& Quine, S. (2008). Stuttering and its treatment in adolescence: the perceptions of people who stutter. Journal of Fluency Disorders, 33(2), 81-98.

This study explored what stuttering would mean to adolescents who stutter. It is of significant importance because there is little research done on the period of adolescence, which is considered to be the last phase where chronic stuttering can be prevented before a person who stutters enters into adulthood. The present study was carried out for these purposes: (a) adolescents' experience of stuttering, (b) reasons to receive treatment (or not), (c) obstacles for finding adequate help, (d) experience of therapy, and (e) suggestions to improve therapy for adolescents.

The authors found that stuttering is not always the biggest barrier for adolescent's social life. Stuttering is often accepted by the adolescent's peer group, which is very important for that phase of life. In addition, substantial lack of awareness of stuttering was observed in adolescents, parents and teachers. And having a stutter was not a good enough reason to seek out treatment. These factors may be a barrier to search for help with their speech.

28. Hulit, L. M. \& Wirtz, L. (1994). The association of attitudes toward stuttering with selected variables. Journal of Fluency Disorders, 19(4), :247-267.

The authors interviewed 203 people by using the Stuttering Inventory in order to find out the relationships between attitudes and stuttering upon chosen variables such as age, gender, educational level, knowledge about stuttering, direct exposure to stutterers, and so on. One major finding was that negative stereotypes toward people who stutter appear to be very persistent despite that a lot of research had shown that PWS are normal and well-capable people. This has an important implication for speech-language pathologists in that they need to strive to use every single opportunity to disseminate the correct information about stuttering and educate the public.

29. Irani, F. \& Gabel, R. (2008). School teachers' attitudes towards people who stutter: results of a mail survey. Journal of Speech-Language Pathology and Audiology, 32(3), 129-134. 
Previous findings in the stuttering literature show that people who stutter are subject to being perceived negatively because of their speech. This study is one of the rare investigations that present rather a different picture to those findings.

School teachers in the United States of America teaching students from the kindergarten level to grade 12 were surveyed on a 14-item semantic differential scale in order to find out two goals: their attitudes towards people who stutter, and the effect of familiarity and educational factors on their perceptions of PWS. The results indicated that the school teachers rated both stutterers and fluent speakers positively on the semantic scale, i.e. they exhibited positive attitudes toward PWS. In some items the PWS were viewed even more positively. Familiarity and educational factors did not appear to have a significant impact on the participants' attitudes.

These findings suggest that American teachers may have become more understanding and tolerant of people who stutter due to a variety of modern social changes, e.g. political correctness.

30. James, S. E., Brumfitt, S. M. \& Cudd, P. A. (1999). Communicating by telephone: Views of a group of people with stuttering impairment. Journal of Fluency Disorders, 24(4): 299-317.

This study investigated the attitudes of people who stutter towards the use of telephone. Research has shown that specific situations are more difficult for PWSs, and using the telephone is one of the most difficult and feared situations for many stutterers. Questionnaires were sent out by post to conduct a survey. Analysis of data suggests that the respondents found it harder to make a call than to answer it. Younger adults who stutter and those with severe stuttering were less likely to use the telephone. Many preferred face-to-face communication to telephoning. The possible reasons and implications of those findings are discussed.

31. Kalinowski, J., Stuart, A. \& Armson, J. (1996). Perceptions of stutterers and nonstutterers during speaking and nonspeaking situations. American Journal of Speech, Language Pathology, 5, 61-67.

Much research has confirmed the existence of negative stereotypes toward people who stutter that appear to be widespread in society and resistant to change. However, according to the authors, previous studies did not pay enough attention to the pervasiveness of the stereotypes, and failed to specify a speaking situation. The authors speculated that the negative stereotypes might disappear if speech factor is removed from the context. Therefore, the authors attempted to find out the public 
perceptions of an adult male stutterer and nonstutterer in speaking versus nonspeaking situations.

A telephone survey was conducted to 188 participants on two 25 -item semantic differential scales. Analysis of the data presented a startling finding was that the stutterer was still perceived negatively in speaking or nonspeaking situations. From these findings, the authors made a compelling argument that the origin of the stereotypes comes from the stuttering behaviour, because the saliency and vividness of stuttering behaviour (e.g. facial torsion or physical struggle) are so strong that the personality traits associated with stutterers go beyond speaking situations.

32. Klassen, T. \& Makhamra, S. (1997). Differences in attitudes toward stutterers, in general, and toward one stutterer, in particular. Journal of Fluency Disorders, 22(2), 144.

Research has demonstrated that the public tend to associate people who stutter with negative personality characteristics. Unlike the previous studies in which the attitudes of groups (teachers, clinicians, etc.) were investigated in general, this study looked at the attitudes of 3 groups of non-stuttering speakers (students, colleagues, and friends) toward one stutterer. It was hypothesized that respondents would show slightly more positive attitudes toward one individual in comparison to the generalized other.

33. Klein, J. F. \& Hood, S. B. (2004). The impact of stuttering on employment opportunities and job performance. Journal of Fluency Disorders, 29(4): 255273.

This investigation looked at how people who perceived their stuttering in their workplaces, especially its impact on job performance and employability. A 17-item questionnaire was administered to 232 participants. The major finding of the study was that stuttering was perceived as a big handicap in the working lives of PWS. The majority (70\%) of the respondents reported that stuttering hinders one's possibility of being employed or promoted. Many answered that they thought employers had negative perceptions of people who stutter.

Results indicated that stuttering affected people's choices of vocation, too. About a half of the respondents said they selected a job that required little speaking, and $20 \%$ declined a new job or promotion due to their speech. Female stutterers tend to view stuttering to be less handicapping than males, and stutterers in minority ethnic groups considered their stuttering more disadvantageous than the Caucasian group. The finding that stuttering is perceived to be a handicap has critical implications for clinicians who work with PWS. 
34. Klompas, M. \& Ross, E. (2004). Life experiences of people who stutter, and the perceived impact of stuttering on quality of life: Personal accounts of South African individuals. Journal of Fluency Disorders, 29(4), 275-305.

This study examined the perceived impact of stuttering on the quality of life of adults who stutter in South Africa. Sixteen adults were recruited and interviewed on a wide range of life domains such as education, social life, employment, speech therapy, family and marital life, and identity, beliefs and emotions.

Important findings indicated that stuttering had an effect on most of domains of their life. Most participants reported that stuttering influenced their academic performance (especially oral presentation) and relationships with teachers and classmates. But stuttering did not appear to hinder their ability to make friends although people showed negative reaction to their stuttering. At work most participants responded that stuttering did not negatively influence their choice of profession and relationships with colleagues. However, their work performance and chances for promotion were believed to be adversely affected by stuttering. Most of them believed that speech therapy had a good impact on their life, and they did not think their relationships with family and marriage were not too greatly influenced by stuttering. Nevertheless, many pointed out that stuttering did have a huge impact on their self-esteem, self-image and self-identity. The implications of these findings for clinical settings and practice are discussed and some detailed suggestions are given at last.

35. Langevin, M. \& Hagler, P. (2004). Development of a scale to measure peer attitudes toward children who stutter. In A. K. Bothe (Ed.), Evidence-based treatment of stuttering: Empirical bases and clinical applications (pp. 139171), Mahwah, N.J.: Lawrence Erlbaum Associates.

The authors begin the chapter by pointing out that, although attitudes towards adults who stutter have been widely investigated, there is a lack of data on attitudes towards children who stutter (CWS). They argued that there was a pressing need to gather object data toward peer attitudes towards CWS. The chapter talks about the details of their study that examined the process of developing an instrument to evaluate these attitudes.

The instruments that the authors developed were labelled as the Peer Attitudes Toward Children who Stutter-40 item Scale (PATCS-40) and PACT-20 item Scale (PACTS-20). The two scales were tested on how reliable they could be as a measurement tool on various aspects such as test / re-test reliability, concurrent validity, predictive validity and so on. The authors tentatively concluded that PATCS-40 seems to be a reliable tool to assess peer attitudes. This chapter provides 
informative explanations on the development process of an attitude measurement instrument, which later forms the basis to evaluate the effectiveness of educational intervention.

36. Lass, N. J., Ruscello, D. M., Schmitt, J. F., Pannbacker, M., Orlando, M. B., Dean, K. A., Ruziska, J. C., \& Bradshaw, K.H. (1992). Teachers' perceptions of stutterers. Language, Speech, and Hearing Services in Schools, 23, 7881.

In this study 103 elementary and secondary school teachers responded to a questionnaire in which they were instructed to provide adjectives that described four hypothetical persons who stuttered (8-year-old male and female children who stutter, adult male and female stutterers). The results showed that the majority of the respondents held negative perceptions towards the hypothetical stutterers. Among the 287 adjectives that were in the questionnaire, more than $70 \%$ of those that were chosen indicated negative personality traits. An interesting finding was that the biggest number of adjectives was used to describe the male child who stuttered. The authors speculated this might have been to do with the participants' exposure to children at their schools.

The importance of the perceptions of teachers is noted because of its key role in the educational process. Their negative perceptions of children who stutter may have a harmful influence on their behaviour toward the children. For this reason the authors argue that teachers need to be educated to draw a distinction between the person who stutters and his/her stuttering.

37. Leahy, M. M. (1994). Attempting to ameliorate student therapists' negative stereotype of the stutterer. European Journal of Disorders of Communication, $29,39-49$.

Previous research has shown that negative stereotypes of people who stutter are widespread in society, held by the general public as well as many professionalseven by speech language therapists. Therefore, this study examined the attempts to alter the negative views of therapy students on stutterers.

The students received education on the impact of negative stereotyping and developed their understanding on stuttering. Some were involved in treatment and some worked directly with clients with fluency disorder for a short period of time. Then they filled up a semantic differential scale on what they thought of their clients after each session. Analysis of the data indicated that only knowledge and/or awareness of stuttering was not strong enough to cause changes in their attitudes. First-hand experience of working with stutterers appeared to have generated some 
positive attitudes towards stutterers. Therefore, the findings suggest that, though negative stereotypes are hard to change, there are ways to improve them.

38. McClure, J. \& Yaruss, S. (2003). Stuttering severity suggests success of attitude-changing treatment. ASHA Leader, 8(3), 19.

This article introduces the results of the survey that the National Stuttering Association (NSA) in the United States conducted on many aspects of various stuttering treatments. The main findings are (a) that treatments that put emphasis on the changes of one's attitude seem most successful for people who stutter and (b) active participation in self-help groups help them to overcome harmful impacts of stuttering.

The NSA interviewed more than 700 persons and about $50 \%$ of the respondents reported that improving their attitudes toward speech and stuttering was a critical factor for their success in recovery from stuttering. These findings may be able to provide some groundwork for more detailed research.

39. MacKinnon, S. P., Hall, S. \& Maclntyre, P. D. (2007). Origins of the stuttering stereotype: Stereotype formation through anchoring-adjustment. Journal of Fluency Disorders, 32, 297-309.

The widespread stereotype of people who stutter tends to be very negative in society. This phenomenon was explained by the anchoring-adjustment theory which posited that the negative stereotype stems from a process during which normal speakers first anchor the stereotype that they feel during moments of normal speech disfluency and adjust based on their heuristic judgement. This aim of this study was to test the validity of this hypothesis by revisiting White and Collins (1984)'s research.

Results lent support to the anchoring-adjustment hypothesis and demonstrated a similar stereotype that was observed in past research. The findings of this study suggest that the negative stereotype of stutterers is formed through generalization and adjustment from people's own experience during normal disfluency, which provides useful guide to the formation of stereotypes.

Note: White, P. A. \& Collins, S. R. (1984). Stereotype formation by inference: A possible explanation for the "stutterer" stereotype. Journal of Speech and Hearing Research, 27, 567-570. 
40. Manning, W. H., Burlison, A. E., \& Thaxton, D. (1999). Listener response to stuttering modification techniques. Journal of Fluency Disorders, 24(4), 267280.

In this study, ordinary listeners were instructed to listen to and appraise two conditions of a stutterer's speech: a Stuttering Only condition and a condition of Stuttering + Stuttering modification techniques. The purpose was to see what kind of response listeners would show to a speaker who was actively managing his stuttering with the techniques of cancellation and pullouts. The authors hypothesized that listeners would respond more favourably to the person's efforts to manage his stuttering.

The results turned out to be opposite to the authors' hypothesis. The participants preferred the Stuttering Only conditions. When the speaker spoke with the techniques, he was perceived as more handicapped. This finding may provide possible explanation for the common cases of post-treatment relapse.

41. Miller, S. \& Watson, B. C. (1992). The relationship between communication attitude, anxiety, and depression in stutterers and nonstutterers. Journal of Speech and Hearing Research, 35, 789-798.

There are widespread stereotypes in society about people who stutter as being anxious, depressed, nervous and tense than nonstutterers. To assess these stereotypes this study investigated self-perceptions of state and trait anxiety, depression and communication attitude in a group of stutterers and another group of nonstutterers.

Results indicated that there were no significant differences between the two groups on measures of trait and state anxiety and depression. Anxiety and depression did not appear to be related to self-evaluations of stuttering severity. But a positive correlation was observed between stuttering severity and communication attitude, i.e. the more severe one's stuttering is, the more negative his or her communication attitude is. This poor attitude towards speaking is thought to be a natural consequence of stutterers' negative communication experiences. These findings support the notion that clinicians should incorporate a therapeutic approach that can address more than the client's speech.

42. Patterson, J. \& T. Pring (1991). Listeners attitudes to stuttering speakers: no evidence for a gender difference. Journal of Fluency Disorders, 16(4), 201205. 
This study is a replication of the research by Burley and Rinaldi (1986). In the previous study, Burley and Rinaldi found that there was a gender difference in the perceptions of people who stutter: men tend to rate stutterers more natively than women.

The authors pointed out that the previous study was flawed because it did not include a control group of fluent speakers. This control group would have been essential to interpret their findings correctly. The gender difference was not observed in the present study though the listeners' negative perceptions toward stutterers was seen.

Note: Burley, P. M. \& Rinaldi, W. (1986). Effects of sex of listener and of stutterer on ratings of stuttering speakers, Journal of Fluency Disorders, 11(4), 329-333.

43. Ratner, N. B. \& Silverman, S. (2000). Parental Perceptions of Children's Communicative Development at Stuttering Onset. Journal of Speech, Language, and Hearing Research, 43(5), 1252-1262.

Some researchers suggested that the beliefs systems of parents of young children who stutter (PCW) are somewhat different from those of parents of nonstuttering children. These PCW are hypothesized that they have unrealistic expectations on their children's linguistic abilities being less developed than their actual skills. To determine the validity of this hypothesis, this study examined the understanding of parents of children who showed the onset of stuttering symptoms about the current level of their children's linguistic development.

The communication abilities of 15 stuttering and non-stuttering children were measured, and their parents were also administered on their understanding of their children's communicative development. Results showed that the stuttering children exhibited a little bit poor linguistic performance than nonstuttering peers. This study is one of the first investigations that provides insight to the role of parental belief on the onset of stuttering in children.

44. Ruscello, D. M., N., Lass, N. J., Schmitt, J. F. \& Pannbacker, M. D. (1994). Special educators' perceptions of stutterers. Journal of Fluency Disorders, 19(2), 125-132.

In this study the researchers used a questionnaire to find out what perceptions special educators would have toward people who stutter. The respondents were instructed to provide adjectives that they thought were appropriate to describe four hypothetical individuals who stuttered (a female child, male child, female adult, and male adult stutterer). 
Most respondents chose adjectives showing negative personality characteristics, which lent support to the research findings that stuttering affects listeners' perceptions of the stuttering speaker's non-speech personality traits. The interesting result was that the biggest number of adjectives was seen in male child who stutters. This may be related to special educators' most exposure to male children. The authors emphasize that the findings have important implications to special educators. For example, they should be educated to be able to make the distinction between the speech disorder and the person who stutters.

45. Schaeffer, N. \& Eichorn, N. (2001). The effects of differential vowel prolongations on perceptions of speech naturalness. Journal of Fluency Disorders, 26(4), 335-348.

One of the important concerns in stuttering treatment is speech naturalness, i.e. the degree to which how natural the speech of a treated stutterer is perceived by the listener. Prolonged speech, where one lengthens vowel sounds or prolongs the entire speech, is widely used to treat stuttering. However, that technique is often perceived to sound unnatural to listeners. To address this problem, the authors attempted to examine the relationship between the duration of prolonged vowels and the perception of speech naturalness.

The findings indicated that the extent of vowel duration does have an impact on listener's perception of speech naturalness. Vowels prolonged at 200\% were perceived as unnatural, and vowels at $150 \%$ were thought to be natural by $80 \%$ of the respondents. This study provides rare quantified data about the acoustic parameters that determine the perception of naturalness of treated stutterers' speech, and the data could be used to enhance treatment outcomes.

46. Silverman, F. H. (1990). Are professors likely to report having "beliefs" about the intelligence and competence of students who stutter? Journal of Fluency Disorders, 15(5-6), 319-321.

Research has shown that some university students who stutter tend to refrain themselves from taking part in class discussions and speak to professors because of their perception that they will be considered less intelligent or competent if their professors and peers find out their speech impediment. This study was conducted to investigate whether professors would really hold such beliefs towards students who stutter. 
A random sample of 87 professors from several American universities were asked to rate a hypothetical student who stutters on bipolar semantic scales. The results showed that the majority of the respondents rated the student on the medium or more positive end of the scales. This finding suggests that, unlike the common belief held by stuttering students, most professors do not hold negative attitudes towards the intelligence and competence of students with stuttering. It could be used as evidence to encourage the students to speak up more in class settings.

47. Silverman, F. H. (2004). Stuttering and other fluency disorders (3rd ed.). Long Grove, III.: Waveland Press.

This book includes a wide range of information on stuttering and its related matters. Particularly useful is a dedicated chapter about the person who stutters (PWS). It provides detailed explanations on the various physiological and psychological characteristics of the PWS. Especially, discussions on the self-concept of the PWS offer good information on how stutterers perceive themselves and how they are perceived by other people. For example, it is worthwhile to note that the PWS's perceptions of themselves influence the level of their fluency.

48. Silverman, F. H. \& Bongey, T. A. (1997). Nurses' attitudes toward physicians who stutter. Journal of Fluency Disorders, 22(1), 61-62.

Though there are many studies that looked at the general public's attitudes towards people who stutter, there are few which deal with attitudes towards people who stutter in terms of their occupational competence. This study, in particular, investigated nurses' attitudes toward physicians who stutter.

Twenty nurses answered a questionnaire containing a 20 -scale semantic differential which postulated a physician who stuttered. It was found that the stuttering physician was viewed generally to be less competent than the non-stuttering counterpart as being considered less mature, intelligent, competent and confident.

49. Siverman, F. H. \& Paynter, K. K. (1990). Impact of stuttering on perception of occupational competence. Journal of Fluency Disorders, 15(2), 87-91.

The goal of this study was to how stutterers would be perceived than non-stuttering counterparts in the identical profession by the general public. Forty-eight undergraduate students were presented with four types of hypothetical persons (a lawyer, a lawyer who stutters, a factory worker, and a factory worker who stutters), and they rated them on 81 semantic differential scales. 
The respondents rated both the lawyer and factory worker who stutter more negatively than those who do not. Another interesting finding was that the stuttering lawyer was judged more negatively than the factory worker. The authors speculated that this might be because stuttering had a bigger impact on the 'appearance of competence' for the occupations constantly dealing with the general public. At the end of the article, the authors presented noteworthy questions as to the choices of future careers for clients who stutter, and some practical suggestions.

50. Snyder, G. J. (2001). Exploratory research in the measurement and modification of attitudes toward stuttering. Journal of Fluency Disorders, 26(2), 149-160.

Speech-language pathologists' attitudes toward stuttering have been reported to be generally negative and quite difficult to be changed in previous research. The negative stereotypes towards people who stutter are known to stay largely unaltered even after personal exposure to stuttering. This study looked at how resistant or malleable the changes in the attitudes of clinicians would be.

Two groups of postgraduate speech-language pathology students were shown two types of video. One group watched a factual video showing stutterers being able to read passages fluently under the effects of altered auditory feedback (AAF). The other group saw a documentary that told of the life of a young girl who stuttered severely and the emotionally-charging process of her treatment. The research investigated whether the students' attitudes were changed after being exposed to the two types of stimuli.

The results indicated that some changes in the perceptions were observed but they were not significant enough to suggest that the participants' attitudes had been significantly modified. Although this study did not succeed in yielding its intended purpose, it did lend support to the findings of previous studies that people's attitudes are not easily changed.

51. Starkweather, C. W. \& Givens-Ackerman, J. (1997). Stuttering. Austin, Texas: Pro-Ed.

This book is a general introductory book about stuttering providing with a wide range of information. It covers from the definition of the disorder from the viewpoints of clinicians as well as stutterers themselves, to the practical guidelines in stuttering treatment.

The book contains valuable information on attitudes towards people who stutter, which can be found with the keyword index at the back such as perception, attitude 
and listeners. The index section provides a good list of keywords and expands from simple core keywords. Those expansive indexed words provide users with an efficient and fast reference guide for researchers who are interested in such topics.

52. Susca, M. \& Healey, E. C. (2001). Perceptions of simulated stuttering and fluency. Journal of Speech, Language and Hearing Research, 44, 61-72.

This article discusses the perceptions of ordinary listeners to digitally produced simulation of stuttered speech with different levels of disfluency. A speech sample was attained from a male adult who stuttered and additional four samples were made with various levels of stuttering $(0 \%, 5 \%, 10 \%, 15 \%)$, along with treated and normal speech. Each of the 60 participants listened to only one of the 6 speech samples randomly, and provided both quantitative and qualitative judgements.

Results show that listener perceptions were indeed influenced by the changes in levels of fluency and stuttering in speech samples. As the level of stuttering increased, the listeners gave lower ratings to the samples. Also, evaluations on the samples tended to become more negative with increased levels of disfluency. This study shows the importance of the role of listener perception plays to a stutterer's communicative ability.

53. St. Louis, K. O., Reichel, I. K., Yaruss, J. S. \& Lubker, B. B. (2009). Construct and concurrent validity of a prototype questionnaire to survey public attitudes toward stuttering. Journal of Fluency Disorders, Article in Press, doi:10.1016/j.jfludis.2009.02.001

Past studies have shown that negative attitudes and stereotypes towards people who stutter exist and widespread in the society. To reduce these negative perceptions, an international task force called the International Project on Attitudes Toward Human Attributes (IPATHA) was formed in 1999. One of its objectives was to develop a survey tool that could effectively measure public attitudes toward PWS anywhere in the world. Their efforts led to the birth of the Public Opinion Survey of Human Attributes (POSHA) and its Experimental Edition (POSHA-E).

The authors explained the three main types of validity: content, construct, and concurrent validity. The issue of content validity with POSHA-E was dealt with by the IPATHA in 2008 but the rest two were not satisfactorily addressed. Therefore, this article tried to estimate construct and concurrent validity of the POSHA-E. The results of the experiment suggest that the POSHA-E showed reasonably satisfactory levels of construct and concurrent validity, which means that it is a reliable instrument to measure changes in attitudes. 
54. Vanryckeghem, M. \& Brutten, G. J. (1996). The relationship between communication attitude and fluency failure of stuttering and nonstuttering children. Journal of Fluency Disorders, 21, 109-118.

The purpose of this study was to examine whether there would be a relationship between speech-related beliefs (mal-attitude toward speech) and stuttered speech of grade-school children who do and do not stutter, and to find out its nature if there is any.

Fifty-five Belgian children were tested on a Dutch version of the Communication Attitude Test (CAT). The results showed that their CAT scores and the degree to which they produced speech disruptions were correlated in stuttering children, which suggests the existence of the relationship between attitudes and stuttering.

This study is one of the first studies which investigated the possible relationship between children's attitudes toward their speech and to the degree to which they produced fluency failures.

55. Vanryckeghem, M., Hylebos, C., Brutten, G. \& Peleman, M. (2001). The relationship between communication attitude and emotion of children who stutter, Journal of Fluency Disorders, 26, 1-15.

The relationship between stuttering and a negative attitude toward speech and the act of speaking is the main focus of this investigation. It has been known that stuttering severity is correlated to mal-attitude and negative emotion. Therefore, this study tried to discover whether negative emotion and speech-related mal-attitude would covary with each other.

The Communication Attitude Test (CAT) was administered to 143 school children aged between 7 and 13 years in Belgium. The results showed a positive correlation between mal-attitude and negative emotion, and those two factors tended to increase with increment in age and stuttering severity. What these findings suggest is that it is crucial to detect and intervene the child's stuttering as early as possible because it is associated with the cognitive and emotive developments of children.

56. Vanryckeghem, M., Brutten, G. J. \& Hernandez, L. M. (2005). A comparative investigation of the speech-associated attitude of preschool and kindergarten children who do and do not stutter. Journal of Fluency Disorders, 30(4), 307-318.

Past research has found that children who stutter, as young as 6 years of age, possess a more negative attitude towards their speech than their peers. Based on these 
findings, the authors investigated the attitude toward speech of stuttering children aged between 3 and 6 with a self-report instrument called the KiddyCAT

(Communication Attitude Test), which measures children's attitudes towards their stuttering.

Analysis of the data obtained from this study exhibited that very young children who stuttered held a more negative speech-related attitude than their non-stuttering counterparts. This finding is in line with previous research findings but presents contrasting evidence to the conventional belief that negative attitudes towards stuttering do not develop long before its onset.

The findings of this study have crucial implications to treatment for youngsters who stutter, and emphasize the important need to evaluate their attitude toward speech.

57. Watson, J. B. (1995). Exploring the attitudes of adults who stutter. Journal of Communication Disorders, 28, 143-164.

This article was written in an attempt to facilitate clinicians' understanding of the issues of their clients who stutter and how to deal with them effectively. The author points out, although that the relations between stuttering and attitudes have been one of research focus topics for a long time, many clinicians still seem to struggle to address the attitude problems of adults who stutter.

It provides a range of practical information on attitudes for clinicians: the nature of attitudes, detailed explanations on attitudinal domains (communication, stuttering, self and therapy), and assessment issues. A number of studies which looked at communication attitudes and characteristics of adults who stutter are introduced. Plus, issues related to intervention and future research are also discussed.

58. Weisel, A. \& Spektor, G. (1998). Attitudes toward own communication and toward stutterers. Journal of Fluency Disorders, 23(3), 157-172.

The researchers looked into the relationship between people's attitudes toward their own communication and attitudes toward stutterers. They tested the validity of the Inference Theory which states that the negative stereotype toward stutterers widespread in the general population is the result of people's inference. That is, fluent speakers make inferences toward personality traits of stutterers on the basis of their own experiences and feelings during the moment of normal dysfluency.

One-hundred-sixty-four adolescents rated their attitudes towards their own communication and their attitudes towards adolescents who stutter. Analysis of the data revealed a mild positive correlation between the two variables, which provides only partial support to the Inference Theory. Besides, a gender difference in the 
perceptions of stutterers was not found. Based on the results the authors emphasize that the interpretation of the Inference Theory should be made with caution.

59. Williams, D. F. \& Diaz, C. F. (2006). The stereotyping of people who stutter. In D. F. Williams, Stuttering recovery: Personal and empirical perspectives (pp. 75-82). Mahwah, NJ: Lawrence Erlbaum Associates.

This chapter discusses some conceptual aspects of stereotyping and stereotypes related to people who stutter. First it starts with a discussion on why stereotyping occurs in humans, and then talks about what this implies for PWS. On the basis of their own experiences in relation to speech behaviours, ordinary people tend to have stereotypes of PWS as being nervous, shy, withdrawn, anxious, and having other negative personality characteristics. These stereotypes can be potentially harmful to PWS because they may have negative effects on them. For example, they could lose possible opportunities for job promotion or better education due to the negative perceptions held against them.

The authors conclude the chapter by presenting the ways how to deal with the stutterer stereotypes, which makes the chapter worthwhile to read. They emphasize that it is critical for PWS to realize how they might be perceived and to learn what they can do about them.

60. Yovetich, W. S., Leschied, A. W. \& Flicht, J. (2000). Self-esteem of schoolage children who stutter. Journal of Fluency Disorders, 25(2), 143-153.

This study investigated the issue of self-esteem of school-age children with a stuttering disorder. The authors recognize that growing up with stuttering can exert negative influences on self-perception, and in particular, self-esteem. Therefore, they carried out this research bearing in mind that self-esteem is an important factor in the treatment settings of stuttering.

Twenty-five elementary pupils with the age ranged from 7 to 11 years were assessed by comparing their self-esteem scores to normative data. No significant differences were found between the participants and any other school-age children. Their results contradict to the findings of the previous research of similar kind. 


\section{Generic Index}

$\begin{array}{ll}\text { A } & \\ \text { Acknowledgement tactic } & 7 \\ \text { Adolescents } & 4,5,27,58 \\ \text { Adults } & 22,23,24,34,35,57 \\ \text { African American } & 12 \\ \text { Anxiety } & 4,10,41 \\ \text { Arts } & 2 \\ \text { Attitude, } & \\ \quad \text { measurement } & 35,50,53 \\ \quad \text { modification } & 50, \\ \quad \text { change of } & 1,3,10,26,29,37,50 \\ \quad \text { shift } & 11 \\ \text { Australia } & 9,11\end{array}$

B

Belgium 13, 55

Beliefs about stuttering

$1,18,43,46,54,56$

Brazil

13

C

Canada 16

Cause 9

Children

$\begin{array}{ll}\text { preschool, } & 56 \\ \text { kindergarten } & 29,56 \\ \text { school-aged } & 20,60 \\ \text { a } & 13 \\ \text { icians } & 32,50,51,57\end{array}$

Communication

$\begin{array}{ll}\text { apprehension } & 4 \\ \text { competence } & 4 \\ \text { attitude toward, } & 14,41,54,55,57 \\ \text { munication Attitude } & 14,54,55,56\end{array}$

Test (CAT) 


\section{D}

Depression 41

Disclosure 5, 26

E

Employment

33,34

Ethnicity

12,33

F-G

Factory worker 49

Fluency $\quad 8,19$

Fluency shaping 8

Follow-up 8

Gender difference $\quad 42,58$

I

Identity

12, 34,

Intelligence

$7,9,20,46$

Intervention

$10,11,19,35,57$

IPATHA

53

J

Job $\quad 8,33,59$

competence, $\quad 48,49$

promotion, $\quad 8,59$

performance, $\quad 33,34$

Johnson's theory 10

K

KiddyCAT 56

Kuwait 1

$\mathbf{L}$

Lawyer $\quad 49$

Lidcombe Programme $\quad 11$ 
Life

choices, $\quad 12$

experience, $\quad 12$

quality of, $\quad 34$

Likert scale $\quad 18,26$

Listener, attitude $\quad 42$

Listeners 24, 26, 40, 42, 45

\section{M-N}

Minority

12,33

New South Wales, Australia 9

Newfoundland 16

Nurses $\quad 48$

O-P

Occupational competence $\quad 48,49$

- also see job competence

Parental influence

10

Parents

$1,6,10,11,27,43$

Peer group

18,27

Personality

$6,7,17,20,24,31,32,36,44,58,59$

Physicians

48

POSHA

1,53

POSHA-E

53

PRCA-24 4

Professors 17

Public awareness $\quad 13,27,37$

Public knowledge

- see public awareness

$\mathbf{R}$

Reactions

physiological 23

psychological 23

Recovery

$19,38,59$

unassisted

19

Relapse

8,40 
Response

of listeners,

$7,23,24,40$

physiological,

psychological,

23

S

School

elementary $\quad 36,60$

secondary $\quad 36$

Self-conception 22

Self-esteem 5, 34

Self-perception $\quad 4,19,41,60$

Self-recovery 19

- also see recovery

South Africa 34

SPCC 4

Special educators $\quad 44$

Stereotype $\quad 5,9,16,24,25,28,31,37,39,50,53,58,59$

Stigma 5

Students $\quad 17,18,20,29,37,46,49,50$

Stutterers

exposure to $\quad 1,9,28,36,44,50$

labelling 15

Stuttering modification $\quad 40$

Stuttering severity $\quad 7,18,21,22,38,41,55$

$\mathbf{T}$

Teachers 27, 29, 34, 36

Teenagers - see adolescents

Telephone, use of $\quad 30$

Therapists $\quad 11,12,21,37$

Treatment $\quad 8,13,14,27,35,37,38,40$

U

United Kingdom (UK) 11

United States of America (USA) $\quad 11,17,25,29,46$ 
Word Count: 13, 843 (less the Index) or 14,282 in total 